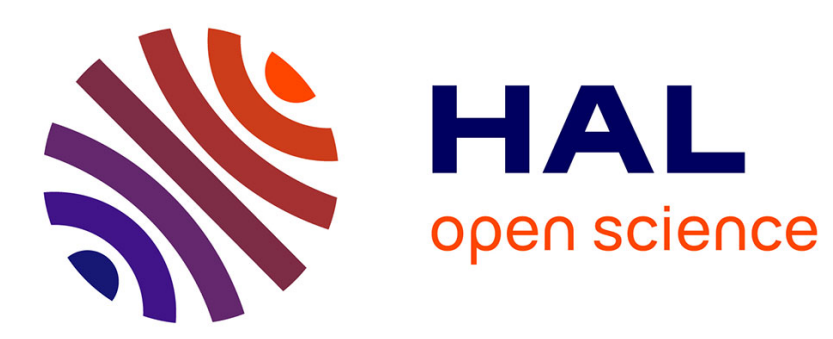

\title{
Effects of species invasion on population dynamics, vital rates and life histories of the native species
}

Simone Vincenzi, Alain Crivelli, Dušan Jeseňsek, Ellen Campbell, John Garza

\section{To cite this version:}

Simone Vincenzi, Alain Crivelli, Dušan Jeseňsek, Ellen Campbell, John Garza. Effects of species invasion on population dynamics, vital rates and life histories of the native species. Population Ecology, 2019, 61 (1), pp.25-34. 10.1002/1438- . hal-02409725

\section{HAL Id: hal-02409725 \\ https://hal.science/hal-02409725}

Submitted on 13 Dec 2019

HAL is a multi-disciplinary open access archive for the deposit and dissemination of scientific research documents, whether they are published or not. The documents may come from teaching and research institutions in France or abroad, or from public or private research centers.
L'archive ouverte pluridisciplinaire HAL, est destinée au dépôt et à la diffusion de documents scientifiques de niveau recherche, publiés ou non, émanant des établissements d'enseignement et de recherche français ou étrangers, des laboratoires publics ou privés. 


\section{Effects of species invasion on population dynamics, vital rates and life histories of}

the native species

Simone Vincenzi1,2 | Alain J. Crivelli3 | Dušan Jeseňsek4 | Ellen Campbell1,2 | John C. Garza1,2

1 - Institute of Marine Sciences, University of California, Santa Cruz, Santa Cruz, California

2- Fisheries Ecology Division, Southwest Fisheries Science Center, National Marine Fisheries Service, Santa Cruz, California

3-Station Biologique de la Tour du Valat, Arles, France

4-Tolmin Angling Association, Most na Soci, Slovenia

Correspondence : Simone Vincenzi, Institute of Marine Sciences, University of California, Santa Cruz, 110 McAllister Way, Santa Cruz, CA 95060. Email: simon.vincenz@gmail.com

How to cite this article: Vincenzi S, Crivelli AJ, Jeseňsek D, Campbell E, Garza JC. Effects of species invasion on population dynamics, vital rates and life histories of the native species. Popul Ecol. 2019;61: 25-34. https://doi.org/10.1002/1438$390 \times .1004$

\section{Abstract}

Invasions occurring in natural environments provide the opportunity to study how vital rates change and life histories evolve in the presence of a competing species. In this work, we estimate differences in reproductive traits, individual growth trajectories, survival, life histories and population dynamics between a native species living in allopatry and in sympatry with an invasive species of the same taxonomic Family. We used as a model system marble trout Salmo marmoratus (native species) and rainbow trout Oncorhynchus mykiss (non-native) living in the Idrijca River (Slovenia). An impassable waterfall separates the stream into two sectors only a few 100 meters apart: a downstream sector in which marble trout live in sympatry with rainbow trout and an upstream sector in which marble trout live in allopatry. We used an overarching modelling approach that uses tagrecapture and genetic data (>2,500 unique marble and rainbow trout were sampled and genotyped) to reconstruct pedigrees, test for synchrony of population dynamics and model survival and growth, while accounting for individual heterogeneity. The population dynamics of the two marble trout populations and of rainbow trout were synchronous. We found higher prevalence of younger parents, higher mortality and lower population density in marble trout living in sympatry with rainbow trout than in marble trout living in allopatry. There were no differences in the average individual growth trajectories between the two marble trout populations. Faster life histories of marble trout living in sympatry with rainbow trout are consistent with predictions of life history theory.

\section{KEYWORDS}

demography, growth, marble trout, pedigree reconstruction, rainbow trout, random-effects models

\section{INTRODUCTION}

The invasion of native communities by alien species is one of the major threats to the stability of ecosystem processes and the persistence of endemic species (Simon \& Townsend, 2003). Although they are one of the biggest challenges conservation biologists are facing (Allendorf \& Lundquist, 2003), invasions occurring in natural environments also provide the opportunity to study how vital rates change and life histories (the timing of key events in an organism's lifetime) evolve in competing species, a central topic of ecology and evolutionary biology (Sakai et al., 2001). In the case of long-lived and mobile organisms, insights from laboratory or small-scale experiments are of limited value, since spatial constraints may force species to interact at unnaturally small scales (Korsu, Huusko, \& Muotka, 2009), the effects of the invasion on the native communities may be appreciated only after a few generations, and the size and direction of the effects may change with changes in the environment (Carroll, 2007).

The study of biological invasions has mostly focused on understanding the mechanism by which non-native species successfully invade new regions. In particular, the focus has been on the environmental (e.g., climate, Jiménez et al., 2011) or ecological (e.g., unoccupied niches, Olden, Poff, \& Bestgen, 2006) conditions facilitating or hampering establishment and spread of the invading species, the life history traits that are associated with invasion success (Capellini, Baker, Allen, Street, \& Venditti, 2015), 
and the adoption of life history strategies by the colonist population that differ from those of the source population (Amundsen et al., 2012). On the other hand, few studies have investigated the overall effects of invasion on the native species, such as effects on its diet, growth, survival, reproduction, life histories and population dynamics (Peterson, Fausch, \& White, 2004).

For life histories, it has often been found that fast life histories increase invasion success (Ruesink, 2005) and that colonists adopt life histories that are faster than those of the source population (i.e., pioneer life histories), since younger age at reproduction and higher reproductive effort may facilitate rapid population growth and spatial expansion when the invading population is small (after the introduction) and throughout the invasion process (establishment and spread) (Burton, Phillips, \& Travis, 2010; Kurz, Heins, Bell, \& von Hippel, 2016). Similarly, fast life histories in the invaded population may help avoid the invasion of the alien species or limit their abundance. For instance, Jones and Closs (2015) found that native galaxiid species (small freshwater fish living in the Southern Hemisphere) in New Zealand cooccurred with alien salmonids only when possessing fast life histories. In contrast, galaxiid species with slow life histories were excluded from salmonid-invaded reaches even when salmonid densities were low.

Native species may also respond adaptively to biological invasions (Carroll, 2007; Strauss, Lau, \& Carroll, 2006), but testing the hypothesis of adoption of faster life histories by the invaded population as an adaptive response to the invasion-either through adaptive genetic differentiation or phenotypic plasticity-is intrinsically challenging. Variation in extrinsic (e.g., weather, predators and food availability) and intrinsic (e.g., population density) habitat factors determines a large part of intra-specific differences in life histories, behavior and physiology of organisms (Southwood, 1977). As habitats differ geographically and temporally, the distribution of vital rates, life histories and phenotypic traits are expected to vary in space and time (Linhart \& Grant, 1996). It follows that the variation in life histories among invaded and non-invaded populations-or before and after the invasion within the same population - may just reflect genetic adaptations or plastic responses to spatial or temporal variation of the environment and not to the presence of a competitor occupying a similar ecological niche (Strauss et al., 2006). In addition, individual heterogeneity in life history traits complicates teasing apart the effects of individual variation from those of habitat variation and the presence of competing species (Vincenzi, Crivelli, Munch, Skaug, \& Mangel, 2016; Vincenzi, Mangel, Crivelli, Munch, \& Skaug, 2014).

In this work, we combine a fine-grained, long-term, tagrecapture dataset with powerful statistical and modelling methods that take into account individual and temporal heterogeneity in vital rates to estimate differences in individual growth, survival, reproduction, life histories and population dynamics between individuals of a native species living in allopatry or competing with an invasive species, using a model system marble trout Salmo marmoratus (native species) and rainbow trout Oncorhynchus mykiss (non-native species) living in Western Slovenian streams. Salmonids have often been used as model systems in ecology and evolutionary biology, due to their vast geographic distribution, their ecological and life history variability, and their strong genetic and plastic responses to habitat and climate variation (Elliott, 1994; Garcia de Leaniz et al., 2007; Jonsson \& Jonsson, 2011; Stearns \& Hendry, 2003).

Marble trout is endemic to rivers tributary to the upper Adriatic Sea and persists in pure form in the Alps of Western Slovenia and parts of Northern Italy (Sušnik, Pustovrh, Jesenšek, \& Snoj, 2015; Vincenzi, Mangel, Jesensek, Garza, \& Crivelli, 2016). Two of the eight remaining genetically pure populations of marble trout in Western Slovenia are in the Idrijca River, where an impassable waterfall separates fish in Upper Idrijca from a closely related group in Lower Idrijca (Fumagalli et al., 2002). Marble trout in Lower Idrijca co-exist with non-native rainbow trout, which were introduced in the 1960s and have been established since then, but they are absent in Upper Idrijca (Stankovic, Crivelli, \& Snoj, 2015). Given the high similarity of Lower and Upper Idrijca habitats (Vincenzi, Mangel, et al., 2016), this unintended treatment-control experiment allows the study of variation in vital rates, life histories and population dynamics of the native species when competing with an invasive species of the same taxonomic Family.

In models of competition-colonization tradeoff, when two species occupying similar niches meet the better competitor excludes the other (Cadotte, 2007). On the other hand, evolutionary models of community assembly often assume that coexistence of competing species results from the operation of resource partitioning mechanisms (Macarthur \& Levins, 1967). Musseau et al. (2017) found only minor overlap between trophic niches of rainbow and marble trout in Lower Idrijca and between trophic niches of marble trout living in Lower Idrijca and in Upper Idrijca. Although rainbow trout is known to take food from other Salmonids, the niche shift of marble trout when occurring in sympatry with rainbow trout in Lower Idrijca was not caused by a niche replacement of marble trout by rainbow trout. Musseau et al. (2017) also found that marble trout in Upper and Lower Idrijca occupy a high trophic position (3.5 in Upper to 3.9 in Lower Idrijca), which confirms observations of piscivory and 
cannibalism in other marble trout populations. Marble trout in Lower Idrijca showed higher $\delta 13 \mathrm{C}$ than marble trout in Upper Idrijca, which is likely to be caused by the inclusion of rainbow trout as additional prey in the diet of marble trout (Musseau et al., 2017). Marble and rainbow trout living in sympatry are thus competitors for food and space, and we expect effects of this interspecific competition on vital rates, life histories and population dynamics of marble trout living in sympatry with rainbow trout, such as faster growth, earlier reproduction, lower survival and lower population densities in marble trout living in Lower Idrijca (sympatry) than in Upper Idrijca (allopatry).

However, the absence of replicates does not allow for strong inference (sensu Platt, 1964) on the causes of variation in vital rates, life histories and population dynamics; therefore we use the results of the study not to test, but to generate hypotheses on the ultimate and proximate causes of the observed variation. Specifically, we used tag-recapture and genetic data ( $>2,500$ unique marble and rainbow trout were sampled and genotyped) to reconstruct pedigrees and estimate age of parents, model survival using tag-recapture analysis, and model growth using random-effects models that explicitly take into account individual heterogeneity. The overarching data and modelling approach allowed us to test for population synchrony, and estimate differences in population dynamics, proportion of younger parents, individual growth trajectories, and survival between marble trout living in allopatry and in sympatry with rainbow trout. We then discuss the observed variation in life histories in the light of ecological and life history theory.

\section{MATERIAL AND METHODS}

\subsection{Study area and species description}

The Idrijca catchment is pristine and there is neither poaching nor angling in the study area. Marble trout is the only fish species living in Upper Idrijca. Within the Lower (LIdri) and Upper (UIdri) Idrijca study areas, there are no physical barriers impairing upstream or downstream movement of marble and rainbow trout; however, both species are territorial and their lifetime movement is typically limited (Vincenzi, Mangel, et al., 2016). Mean daily water temperatures in LIdri and Uldri over years 2006 to 2013 were 8.1 0.2 and 7.7 0.2 C, respectively (Vincenzi, Mangel, et al., 2016). There is ample spawning habitat in both Lower and Upper Idrijca. Detailed description of the biology and ecology of marble trout can be found in Vincenzi, Mangel, et al. (2016). Marble trout populations are highly genetically differentiated (Fumagalli et al., 2002), persist at low population densities (approximately 600 and 1,250 ha-1 for fish older than young-of-year), are at high risk of extinction due to hybridization with non-native brown trout (Salmo trutta) and the occurrence of extreme events such as flash floods, debris flows and landslides (Vincenzi et al., 2008; Vincenzi, Mangel, et al., 2016; Vincenzi, Mangel, Jesensek, Garza, \& Crivelli, 2017). Brown and marblebrown trout hybrids living in the hybridization zone cannot move into either Lower or Upper Idrijca due to the presence of waterfalls that prevent the upstream movement of fish.

Rainbow trout is a north Pacific species (Gall \& Crandell, 1992) that was introduced in the Adriatic basin of Slovenia in the early 20th century and established self-sustaining stream-resident populations there (Stankovic et al., 2015). Rainbow trout were stocked in the headwaters of the Idrijca River (Upper Idrijca) only once, in 1962. Rainbow trout in the Adriatic basin of Slovenia typically start spawning at age 1 (D. Jeseňsek and A.J. Crivelli, unpublished data).

\subsection{Sampling}

We sampled the rainbow and marble trout populations of LIdri and Uldri bi-annually in June and September of each year from June 2004 to September 2015 for a total of 24 sampling occasions. Fish were captured by electrofishing and total length (L) and weight (W) recorded to the nearest millimetre and gram. If captured fish had $\mathrm{L}>115 \mathrm{~mm}$, and had not been previously tagged or had lost a previously applied tag, they received a Carlin tag (Carlin, 1955) and age was determined by reading scales. Fish are aged as $0+$ in the first calendar year of life, $1+$ in the second year and so on. Subyearlings of both rainbow and marble trout are smaller than $115 \mathrm{~mm}$ in June and September, so fish were tagged when at least age 1+. The adipose fin was also removed from all fish captured for the first time (starting at age 0+ in September), including those not tagged due to small size at age 1+. Therefore, fish with an intact adipose fin were not sampled during previous sampling occasions at age $0+$ or $1+$. Males and females of marble and rainbow trout are morphologically indistinguishable in either June or September; sex was thus assigned in the laboratory using molecular techniques (Yano et al., 2013). 


\subsection{Single-nucleotide polymorphism genotyping}

DNA was extracted from dried fin clips using the DNeasy 96 filter-based nucleic acid extraction system on a BioRobot 3,000 (Qiagen, Inc., Hilden, Germany), following the manufacturer's protocols. Extracted DNA was diluted 2:1 with distilled water and used for polymerase chain reaction amplification of 96 population-specific single-nucleotide polymorphisms (SNPs). SNPs were assayed with 96.96 Dynamic Array integrated fluidic circuits (IFCs) for Genotyping on an EP1 (EndPoint Reader 1) instrument (Fluidigm, Inc.)), using the manufacturer's recommended protocols. Genotypes were called using SNP Genotyping Analysis software (Fluidigm, Inc., South San Francisco, US). Two people called all genotypes independently, and discrepancies in the scores were resolved either by consensus, by re-genotyping, or by deletion of that genotype from the data set. A proportion of individuals were genotyped more than once (e.g., in case of tag loss or when the fish was $<115 \mathrm{~mm}$, and later at tagging), as determined by observed identical genetic profiles and compatible age and length data, and one of the samples was excluded from the analyses. Matching genotypes of individuals with different physical tags is a method of "genetic tagging" that allows reconstruction of the life histories of individuals after tag loss. Mean SD minor allele frequency (MAF) of the SNPS was 0.270 .13 for LIdri_MT (95 polymorphic SNPs, Supporting Information Table S1), 0.270 .14 for UIdri_MT (95 SNPs, Supporting Informa- tion Table S2) and 0.260 .14 for LIdri_RT (83 SNPs, Supporting Information Table S3). Such MAFs with nearly 100 SNPs are sufficient for parent pair/offspring trio reconstruction with high accuracy (Anderson \& Garza, 2006). The final dataset included 1,129 marble trout living in LIdri (LIdri_MT), 610 marble trout living in Uldri (Uldri_MT) and 291 rainbow trout living in LIdri (LIdri_RT) that were identified either as offspring or potential parents.

\subsection{Statistical analyses and hypotheses tested}

We first estimated density of age-classes and then tested for (a) recruitment-driven population dynamics, (b) population synchrony and (c) temporal differences in population densities between the three populations. Then, we reconstructed pedigrees in each population and fitted models of growth and survival to estimate differences in (d) lifetime growth trajectories, (e) probability of survival and ( $f$ ) proportion of young parents between LIdri_MT, LIdri_RT and Uldri_MT.

\subsection{Estimation of population density}

We estimated the density of $0+$ fish only in September, since marble trout normally emerge a few days before the June sampling and rainbow trout emerge in July. We estimated the density of $0+$ fish and fish older than $0+$ using a twopass removal protocol (Carle \& Strub, 1978) and the R (R Development Core Team, 2014) package FSA (Ogle, 2018). Total stream surface of the monitored area (1,084 and 1,663 $\mathrm{m} 2$ for LIdri and Uldri, respectively) was used for the estimation of fish density (in fish ha-1 ). Previous studies (Vincenzi, Mangel, et al., 2016) have found that population dynamics of other marble trout populations living in Western Slovenian streams are driven by recruitment. Following Vincenzi, Mangel, et al. (2016), we tested for recruitmentdriven population dynamics in LIdri_MT, LIdri_RT and UIdri_MT by estimating cross-correlations between density of 0+ fish (D0+) in September (recruitment) and density of older than $0+$ fish $(D>0+) 1$ year later within each population. We also tested for synchrony of population dynamics (“Moran effect," Ranta, Kaitala, Lindström, \& Helle, 1997) of LIdri_MT and LIdri_RT, and LIdri_MT and UIdri_MT. Statistical significance was set at the 0.05 level 2.6

\section{Pedigree reconstruction and age at spawning}

We used a two-step conservative approach for reconstructing pedigrees in the marble and rainbow trout populations (Vincenzi et al., 2017), using the software SNPPIT (Anderson, 2012) and FRANz (Riester, Stadler, \& Klemm, 2009). SNPPIT is tailored for identification of mother-father parent pairs in single generations and does not perform single-parent assignments. FRANz can also infer single parents and can be used to infer parentage in multiple generations. Known parent-offspring relationships can be used by FRANz to estimate genotyping error rate. Marble trout genotypes were analysed with SNPPIT to identify parentpair/offspring trios with a false discovery rate threshold of 0.05 , and these trios were then used in FRANz as known relationships to identify single parent-offspring pairs and additional parent-pair/offspring trios. Further details on pedigree reconstruction are in Text 1 in Supporting Information Appendix S3.

Marble trout in Uldri and LIdri spawn from midNovember to mid-December. Therefore, for example, the eggs of cohort 2011 were fertilized in November-December of 2010 and newborn emerged in June 2011. Rainbow trout in Lower Idrijca spawn in April and offspring emerge in July of the same year (T. W. Lee and A. J. Crivelli, unpublished data). Marble trout are iteroparous. Age at first reproduction varies within and among marble trout populations; pedigree reconstruction in other populations found that marble trout spawn typically at age 3+ and older, with fewer fish spawning at age 1+ and 2+ (Meldgaard et al., 2007; Vincenzi et al., 2017). 
We used a $\chi 2$ test of equality of proportions to test for differences in the proportion of younger parents between LIdri_MT and Uldri_MT. Since the distribution of age at spawning is skewed and potentially biased by some old parents, we only considered parents aged $1+$ and $2+$ (young parents), and 3+ and 4+ (old parents).

\subsection{Growth and body size}

To characterize size-at-age and growth trajectories, we modelled variation in lifetime growth trajectories of marble and rainbow trout living in LIdri_MT, LIdri_RT and UIdri_MT taking into account within-population individual heterogeneity in growth.

The standard von bertalanffy growth function (vBGF; von Bertalanffy, 1957) is

$$
L(t)=L_{\infty}\left(1-e^{-k\left(t-t_{0}\right)}\right)
$$

where $L_{\infty}$ is the asymptotic size, $k$ is a coefficient of growth (in time-1) and to is the (hypothetical) age at which length is equal to 0 . However, to accurately estimate overall, group-specific or individual growth trajectories, we need to take into account individual variation in growth; otherwise, the average trajectory can be substantially pulled up or down by a few long-living fast or slow growers (Vincenzi et al., 2014).

We used the formulation of the VBGF specific for longitudinal data of Vincenzi et al. (2014), in which L $\infty$ and k may be allowed to be a function of shared predictors and individual random effects. In the estimation procedure, we used a log-link function for $k$ and $L \infty$, since both parameters must be non-negative. We set.

$$
\left\{\begin{array}{l}
\log \left(k^{(i j)}\right)=\alpha_{0}+\alpha_{1}(j)+\sigma_{u t} u_{i j} \\
\log \left(L_{\infty}^{(i j)}\right)=\beta_{0}+\beta_{1}{ }^{(j)}+\sigma_{v} v_{i j} \\
t_{0}^{(i j)}=\gamma_{0}
\end{array}\right.
$$

where $u \sim N(0,1)$ and $v \sim N(0,1)$ are the standardized individual random effects, $\alpha_{1}{ }^{(1)}$ and $\beta_{1}{ }^{(1)}$ are group effects (e.g., sex, 11 yearof-birth cohort, population and species), $\sigma_{u}$ and $\sigma_{v}$ are the standard deviations of the statistical distributions of the random effects and the other parameters are defined as in Equation (1).

We thus assume that the observed length of individual $i$ in group $j$ at age $t$ is

$$
L_{i j}(t)=L_{\infty}^{(i j)}\left(1-e^{-k^{(g)}\left(t-k_{i}^{(j)}\right)}\right)+\varepsilon_{i j}
$$

Where $\varepsilon_{\mathrm{ij}}$ is normally distributed with mean 0 and variance $\sigma_{\varepsilon}^{2}$

Since the growth model operates on an annual time scale and more data on tagged fish were generally available in September of each year, we used September data for modelling lifetime growth trajectories. In order to test for differences in growth trajectories, we included three potential categorical predictors ( $\alpha 1$ and $\beta 1$ in Equation 2) of k and L $\infty$ : (a) Species (MT and RT), (b) Population (Lidri_MT, UIdri_MT, LIdri_RT), (c) Cohort. We also tested whether there were large differences in vBGF population-specific models when estimating parameters separately for each population using a standard non-linear regression routine with no random effects (nls function in R) or when using models in Equations (2) and (3).

\subsection{Survival}

Our goal was to estimate variation in survival among populations and to investigate the effects of presence of rainbow trout on survival, time (sampling occasion or season) and successful reproduction.

Two probabilities can be estimated from a capture history matrix: $\phi$, the probability of apparent survival (defined "apparent" as it includes permanent emigration from the study area), and $p$, the probability that an individual is captured when alive (Thomson, Cooch, \& Conroy, 2009). We used the Cormack-Jolly-Seber (CJS) model as a starting point for the analyses (Thomson et al., 2009). We tested the goodness-of-fit of the CJS model with the program Release. The global model (i.e., the model with the maximum parameterization) was a good starting point to model survival and capture probabilities. All other survival models tested were simplified versions of this global starting model, with the potential addition of covariates. From the global model, 
recapture probability was modelled first. The recapture model with the lowest akaike information criterion (AIC) was then used to model survival probabilities.

We modelled the seasonal effect (Season) as a simplification of full-time variation, by dividing the year into two periods: June to September (Summer), and the time period between September and June (Winter). As the length of the two intervals (Summer and Winter) was different ( 3 months and 9 months), we estimated probability of survival on a common annual scale. Previous work has found no or minor effects of population density, water temperature, body size or sex on survival in marble trout (Vincenzi, Mangel, et al., 2016).

Since only trout with $L>115 \mathrm{~mm}$ (aged at least $1+$ ) were tagged, capture histories were generated only for those fish. We first used data for all three populations to estimate the overall differences in survival probabilities among them using population (LIdri_MT, LIdri_RT, UIdri_MT) and sampling occasion or season as predictors of survival. Then, in order to obtain a finer-grained estimation of variation in survival in marble trout, we excluded LIdri_RT from the dataset and modelled survival only in LIdri_MT and UIdri_MT, also in this case using population (LIdri_MT, Uldri_MT) and sampling occasion or season as predictors of survival.

Next, we used a subset of the tag-recapture data set (fish born after the start of tagging, i.e., $\geq 2004$, and only females) for the two marble trout populations to test for costs of reproduction. Spawning successfully (i.e., at least one offspring assigned to the parent) was modelled as a timevarying predictor (Spawn_temp: 1 for the September to June sampling period in which spawning occurred and 0 otherwise). The hypothesis tested is of a lower survival probability of female parents in the months following reproduction in LIdri_MT than in UIdri_MT due to higher costs of reproduction. Models tested included a population component (constant or LIdri_MT/UIdri_MT), a time component (sampling occasion or season) and a spawning component (constant or Spawn_temp).

For each model, we tested additive and multiplicative interactions among predictors. Models were considered to provide the same fit to data when $\triangle A I C$ between models was $<2$ (Burnham \& Anderson, 2002). We carried out the analysis of survival using the package marked (Laake, Johnson, \& Conn, 2013) for R (R Development Core Team, 2014) (Genotype data:

https://dx.doi.org/10.6084/m9.figshare.4244252.v2; Tag-recapture data: https://dx.doi.

org/10.6084/m9.figshare.4244249.v2).

\section{RESULTS}

A paired $t$ test found significantly higher population density in September of fish older than 0+ in UIdri_MT than in LIdri_MT ( $p=$ 0.01 , average difference approximately 250 individual ha-1) and a density of $0+$ fish significantly higher in LIdri_MT than in Uldri_MT ( $p<0.01$, average difference approximately 500 individual ha-1) (Figure 1a). LIdri_RT older than $0+$ were found at much lower densities than LIdri_MT ( $p<0.01$, average difference approximately 550 individual ha-1), but densities of $0+$ were not significantly different between LIdri_RT and LIdri_MT $(p=0.06)$ (Figure $1 b)$.

There were significant cross-correlations with a lag of 1 year between the density of $0+$ and fish older than $0+$ for both LIdri_MT $(r=0.65)$ and UIdri_MT $(r=0.61)$, which suggest that recruitment (i.e., density of $0+$ in September at year $t)$ was driving variation in density of fish older than juveniles. In contrast, the 1-year lagged correlation between the density of $0+$ and fish older than $0+$ for LIdri_RT was not significant. Densities of LIdri_MT and LIdri_RT older than 0+ were cross-correlated with no lag ( $r=0.77$ ), while densities of $0+$ were cross-correlated with no lag only when excluding an outlier (year 2012, $r=0.60$ ). The densities of both $0+$ and older than $0+$ fish of the two marble trout populations were not significantly cross-correlated; however, when excluding the outliers 2007 (for $0+$ ) and 2008 (for older than 0+) (which identify the same process, since the 2007 high recruitment in Uldri_MT led to the high density of fish older than $0+1$ year later, Figure 1 ), the two time series were significantly correlated with no lag (0+: $r=0.63$, $>0+: r=0.62)$.

Some old, big marble trout were found in LIdri (Figure 2), probably due to a large pool there that allowed their survival. VBGF models fitted with no random effects show how the estimated average growth trajectories can be heavily biased by a few long-lived, bigger-at-age marble trout living in Upper and Lower Idrijca (Supporting Information Figure S1), thus making necessary the adoption of models with individual random effects. Random-effects models with Species and Population as predictors of VBGF parameters provided the same fit to data $(\triangle \mathrm{AIC}<2)$. Both average growth trajectories and confidence intervals of LIdri_MT and UIdri_MT almost completely overlapped, while on average rainbow trout grew faster and remained bigger-at-age throughout their lifetimes than marble trout in either population (Figure 2). 
The best model of survival probabilities had survival varying with sampling occasion and population, with survival probabilities consistently higher in Uldri_MT than in LIdri_MT and LIdri_RT (Table 1, Figure 3). When including only marble trout populations, the best models had survival varying with population and sampling occasion (Table 1). The addition of Spawn_temp did not improve model fit after accounting for population and sampling occasion (Table 1).
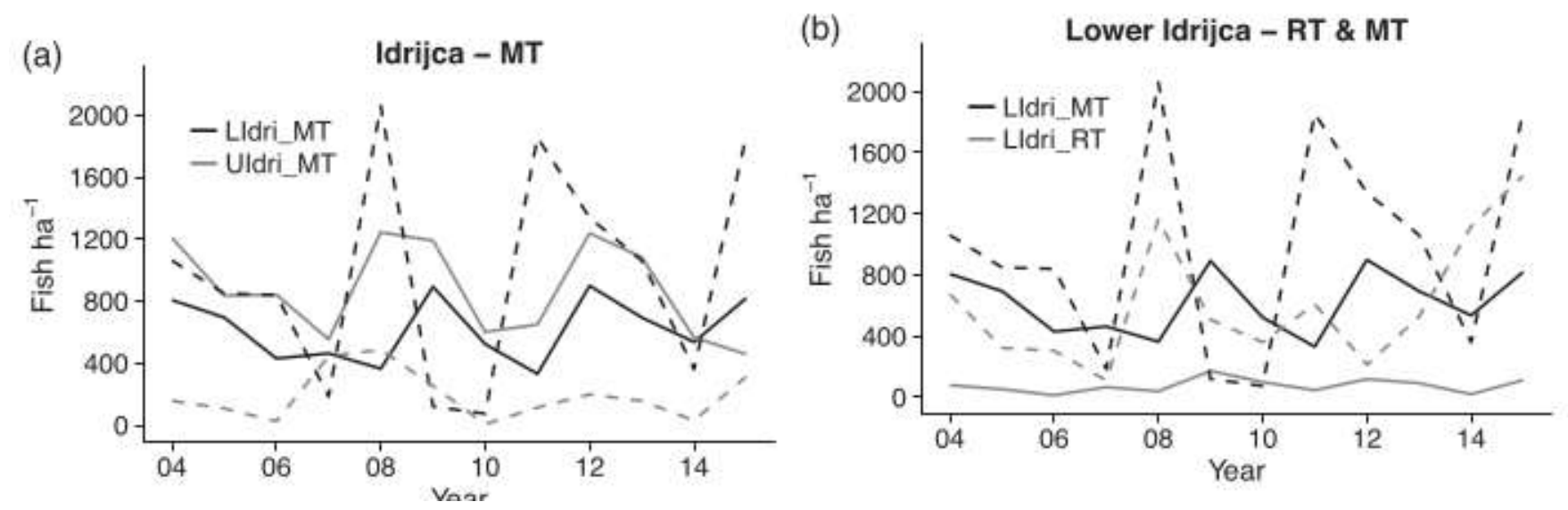

FIGURE 1 (a) Density over time of LIdri_MT and UIdri_MT aged 0+ (dashed line) and older than 0+ (solid line) in September. (b) Density over time of LIdri_MT and LIdri_RT aged $0+$ (dashed line) and older than $0+$ (solid line) in September

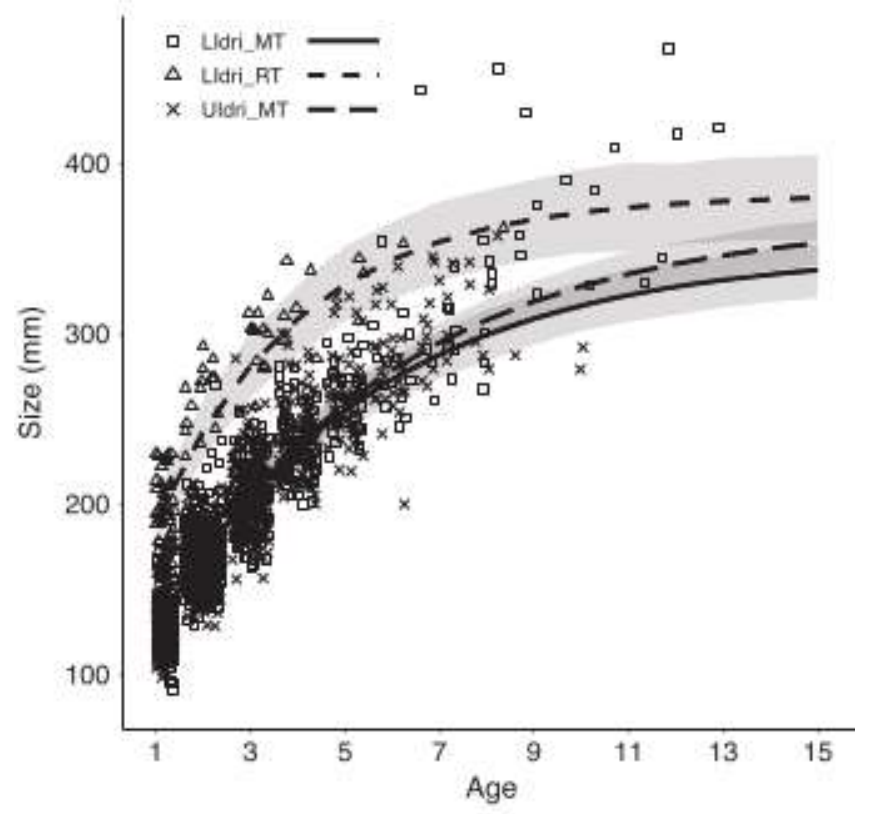

FIGURE 2 Average (i.e., individual random effects for $L \infty$ and $k$ set to 0 ) growth trajectories of LIdri_MT, LIdri_RT and UIdri_MT predicted by the von bertalanffy growth function (VBGF) model with population as predictor of $L \infty$ and $k$. Grey bands are the $95 \%$ confidence intervals of the average trajectories 


\begin{tabular}{|c|c|c|c|c|}
\hline Model & npar & AIC & $\triangle \mathrm{AIC}$ & Weight \\
\hline \multicolumn{5}{|l|}{ All three populations } \\
\hline$\phi(P o p+T i n e)$ & 28 & $6,814.12$ & $0 .(x)$ & 0.97 \\
\hline$\phi$ (Pop * Seasan) & 9 & $6,820.99$ & 6.87 & 0.03 \\
\hline$\phi(P o p)$ & 6 & $6,827.94$ & 13.82 & 0.00 \\
\hline$\phi($ Pop + Seascon $)$ & 7 & 6.827 .97 & 13.84 & 0.00 \\
\hline$\phi($ Pop * Tine $)$ & 72 & $6,845.92$ & 31.80 & 0.00 \\
\hline \multicolumn{5}{|l|}{ Only marble trout } \\
\hline$\phi($ Pop + Time $)$ & 26 & 6.198 .53 & 0.00 & 0.97 \\
\hline$\phi(P o p)$ & 25 & $6,207.06$ & 8.53 & 0.01 \\
\hline$\phi(P o p+$ Seasan $)$ & 24 & 6.207 .89 & 9.36 & 0.00 \\
\hline$\phi($ Pop + Seusone $)$ & 38 & $6,208.59$ & 10.06 & 0.00 \\
\hline$\phi($ Pop * Time $)$ & 37 & $6,223.68$ & 25.15 & 0.00 \\
\hline \multicolumn{5}{|c|}{ Only marble trout females with also spawning as predictor } \\
\hline$\phi(P o p+T i n e+S p a s n$ semp $)$ & 26 & 4.558 .48 & 0.00 & 0.47 \\
\hline$\phi(P o p+T i m e)$ & 25 & 4.558 .59 & 0.11 & 0.45 \\
\hline$\phi(P o p+S p a w n$ temp) & 24 & $4,564.64$ & 6.16 & 0.02 \\
\hline$\phi(P o p)$ & 38 & $4,565.24$ & 6.76 & 0.02 \\
\hline $\begin{array}{c}\phi(\text { Pop }+ \text { Seasoun }+ \\
\text { Spawn temp })\end{array}$ & 37 & 4.566 .12 & 7.64 & 0.01 \\
\hline
\end{tabular}

TABLE 1 Five best models of probability of apparent survival $\phi$ for all three populations (LIdri_MT, UIdri_MT and LIdri_RT), only the two marble trout populations, and only females for the two marble trout

Note: The symbol * denotes interaction.

AIC, akaike information criterion; npar, number of parameters of the survival model; Time, the interval between two consecutive sampling occasions; Season, categorical variable for Summer (June to September) and Winter (September to June); Spawn_temp, categorical variable for females spawning successfully (1) or not (0).

We were able to confidently assign to parent pairs or single parents 36\% of genotyped individuals for Uldri_MT, 45\% for LIdri_MT and 25\% for LIdri_RT (Supporting Information Figure S2). Individuals continued to spawn throughout their lifetime (Supporting Information Figure S3). The proportion of younger parents was higher in LIdri_MT than in UIdri_MT ( $\chi 2=4.98, p=$ $0.02)$, while no difference in proportion of younger parents was found between LIdri_MT and LIdri_RT ( $\chi 2=0.002, p=0.96$ )

(Figure 4). Similar results were obtained when considering only 1+ as young parents.

\section{Discussion}

The population dynamics of the two marble trout populations and of rainbow trout were overall synchronous. We found higher prevalence of younger parents, higher mortality and lower density of individuals older than $0+$ in marble trout living in sympatry with rainbow trout than in marble trout living in allopatry. In contrast, there were no differences in the average growth trajectories between the two marble trout populations. We discuss the observed variation in population dynamics, vital rates and life histories between he two marble trout populations, the pieces of missing infor mation that will improve our understanding of its proximate and ultimate causes, and how the observed variation is con sistent with the predictions of life history theory.

\subsection{Population dynamics and reproduction}

Supported by Musseau et al.'s (2017) hypothesis on the likely inclusion of rainbow trout as additional prey in the diet of marble trout living in Lower Idrijca, our hypothesis is that predatory pressure on rainbow trout juveniles by marble trout older than 1+ caused both the low density of rainbow trout older than $0+$ and the lack of cross-correlation between recruitment and density of older fish in rainbow trout. DNAbased faecal dietary analysis (Valentini, Pompanon, \& Taberlet, 2009) will help us test this hypothesis.

Overall, the population dynamics of marble trout in Upper and Lower Idrijca and of marble and rainbow trout in Lower Idrijca were synchronous, which points to common environmental determinants of temporal variation in vital rates ("Moran effect"). Vincenzi, Mangel, et al. (2016) showed that variation in water temperature alone-over sampling occasions or early in life-did not explain much variation in either survival or growth in marble trout living in Western Slovenian streams, including the Idrijca populations. In addition, Vincenzi, Mangel, et al. (2016) found strong cohort effects on survival and growth in almost all marble trout populations living in Western Slovenia, which suggest that a combination of environmental factors (e.g., food, water flow and temperature) experienced early in life is driving a large part of the variation in vital rates in marble and rainbow trout living in Idrijca. An analysis of spatio-temporal patterns of fluctuation of 57 brown trout populations across France found that the degree of synchrony among sites for the $0+$ fish was significantly related to the degree of hydrological synchrony, in particular synchronous high flows across rivers and streams during the emergence period (Cattaneo, Hugueny, \& Lamouroux, 2003). Future measurement of water flows in Upper and Lower Idrijca with probes or meters and estimation of temporal variation of food-web components would provide a clearer picture of the environmental determinants of synchronous population dynamics. 


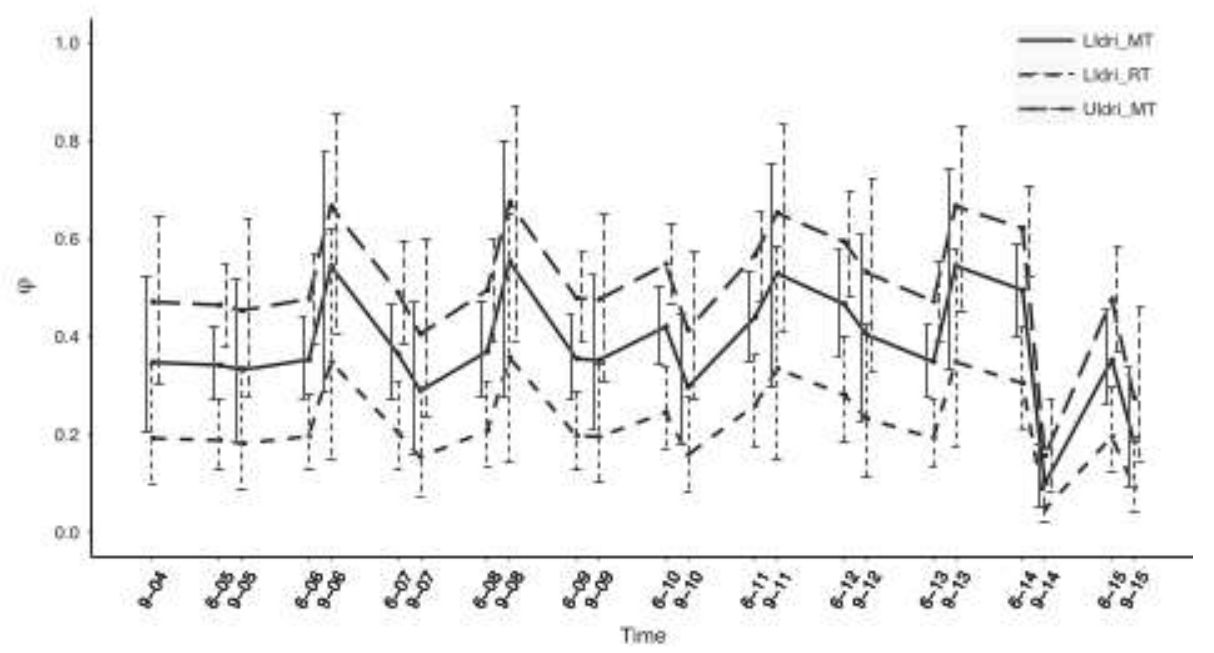

FIGURE 3 Best model of apparent survival when including all three populations, with survival varying by population and sampling occasion (i.e., $\phi[$ Population + Time]). Vertical bars are $95 \%$ confidence intervals
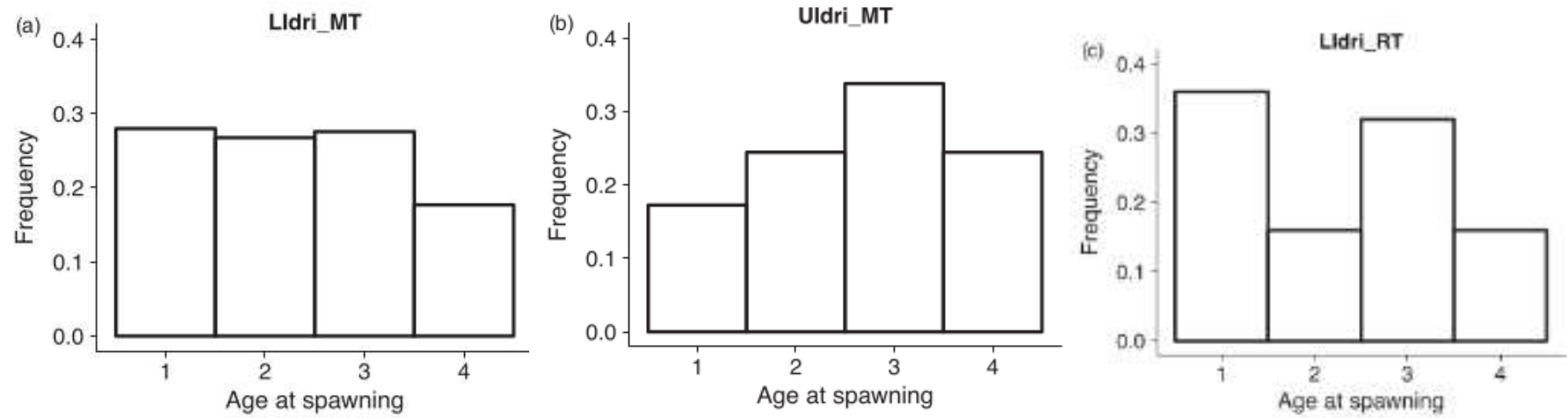

FIGURE 4 Age (up to 4+) distribution of parents in (a) LIdri_MT,(b) UIdri_MT and (c) LIdri_RT

At each sampling occasion, density of juvenile marble trout in allopatry was much lower than that of marble trout in sympatry. The lower density of juveniles in allopatry was due to reproduction occurring mostly in a small tributary of Upper Idrijca located upstream of the two monitored stream stretches; the time passing between emergence of new-borns and sampling in September was not long enough to allow for the arrival of $0+$ in the monitored stream stretches. It follows that estimated recruitment was only a small fraction of real recruitment.

\subsection{Survival}

One of the central tenets of life history theory is the expected tradeoff between survival and reproduction. Vincenzi, Mangel, et al. (2016) hypothesized that lower average survival in marble trout populations exhibiting faster individual growth was caused by the cost of reproduction: faster growth early in life can lead to younger age at sexual maturity when gonadal development is size dependent (Alm, 1959; Craig, 1985; Jonsson, Jonsson, \& Finstad, 2013) and then cause higher mortality of spawners due to energetic limitations (Berg, Thronæs, \& Bremset, 1998). In marble trout living in Upper and Lower Idrijca, we did not find evidence of lower survival probabilities for female parents in the sampling interval (September to June) following spawning. However, most marble trout females spawn each year after becoming sexually mature and the cost of reproduction should not be limited to only those females that reproduced successfully. Thus, even if present, higher costs of reproduction in marble trout living in Lower Idrijca may be difficult to detect using parents as a proxy for spawners. Another hypothesis to explain lower survival of marble trout in sympatry with rainbow trout is more intense competition for hiding places; although the total density of fish in Upper and Lower Idrijca is similar, rainbow trout are bigger than marble trout and this may be due to their more aggressive and/or territorial behavior, with negative effects on marble trout survival rates.

\subsection{Age at spawning, growth and life histories}

We found that marble trout in sympatry had a higher proportion of young parents than marble trout living in allopatry, and the same proportion of young parents as sympatric rainbow trout. Along with lower survival, higher proportion of young parents points to faster life histories in sympatric than in allopatric marble trout. 
It has often been found that fast life histories increase invasion success (Ruesink, 2005) and that colonists adopt life histories that are faster than those of the source population (i.e., pioneer life histories). Similarly, fast life histories in the invaded population may help avoid the invasion of the alien species or limit their abundance. Theoretical and empirical studies have found that fitness is highly sensitive to variation in age at first reproduction (Fay, Barbraud, Delord, \& Weimerskirch, 2016). Age at reproduction varies greatly withinand among populations of the same species, and life history theory predicts a tradeoff between growth and reproduction (Roff, 2007; Stearns, 1992): organisms with a slower pace of life allocate more energy to growth throughout their life and reproduce at older ages, since fecundity and other reproductive traits, such as the ability to secure mates, often increase with size.

However, growth of fish results from the interaction of resource acquisition, availability and allocation (Vincenzi, Crivelli, et al., 2016), along with other factors such as temperature, water flow and length of growing season (Crozier, Zabel, Hockersmith, \& Achord, 2010). According to life history theory, when there is a minimum size for gonadal development, organisms adopting faster life histories should grow faster and then plateau in size after sexual maturity due to allocation of energy to reproduction at the expense of growth. However, despite the presence of a competitor and the shift in diet, marble trout living in sympatry with rainbow trout did not grow differently than marble trout in allopatry, which shows that the acceleration of reproduction may occur without variation in growth.

Phenotypic shifts over contemporary time scales can result from phenotypic plasticity or selection acting on standing genetic variation, and they are most likely a result of a combination of these factors (Hendry \& Gonzalez, 2008). Reproductive traits are heritable (Carlson \& Seamons, 2008), and can thus respond adaptively to changes in the fitness landscape. In marble trout living in streams affected by flash floods causing massive mortalities, Vincenzi et al. (2017) found that fish born after the flash floods had younger mean age at reproduction than fish born before the flash flood. Vincenzi et al. (2017) hypothesized that younger age at reproduction after the flash floods was due to a combination of faster growth due to lower population density and fewer older fish competing for mates. In the case of Idrijca, the age-structure of marble trout in Lower and Upper Idrijca and their fish densities are similar, and average growth trajectories are basically the same; thus other adaptive or plastic processes causing a higher prevalence of younger parents in marble trout living in Lower Idrijca may be at work. Currently on-going common garden experiments will help elucidate the proximal causes of faster life histories in marble trout living in Lower Idrijca.

\section{ACKNOWLEDGMENT}

We thank the employees and members of the Tolmin Angling Association (Slovenia) for carrying out fieldwork since 1993. This study has been funded by MAVA Foundation.

\section{Author Contributions}

S.V., A.J.C. and J.C.G. conceived the ideas and designed methodology; A.J.C. and D.J. collected the data; S.V. and E.C. analysed the data; S.V., J.C.G. and A.J.C. led the writing of the manuscript. All authors contributed critically to the drafts and gave final approval for publication.

\section{REFERENCES}

Allendorf, F. W., \& Lundquist, L. L. (2003). Introduction: Population biology, evolution, and control of invasive species. Conservation Biology, 17, 24-30.

Alm, G. (1959). Connection between maturity, size and age in fishes. Report : Institute of Fresh-water Research, Drottningholm, 40, 5-145.

Amundsen, P. A., Salonen, E., Niva, T., Gjelland, K. O., Praebel, K., Sandlund, O. T., ... Bohn, T. (2012). Invader population speeds up life history during colonization. Biological Invasions, 14, 1501-1513.

Anderson, E. C. (2012). Large-scale parentage inference with SNPs: An efficient algorithm for statistical confidence of parent pair allocations. Statistical Applications in Genetics and Molecular Biology, 11.

Anderson, E. C., \& Garza, J. C. (2006). The power of single-nucleotide polymor phisms for large-scale parentage inference. Genetics, 172, 2567-2582.

Berg, O. K., Thronæs, E., \& Bremset, G. (1998). Energetics and survival of virgin and repeat spawning brown trout (Salmo trutta). Canadian Journal of Fisheries and Aquatic Sciences, 55, 47-53. 
Burnham, K. P., \& Anderson, D. R. (2002). Model selection and multimodel inference: A practical information-theoretic approach. New York, NY: Springer Verlag.

Burton, O. J., Phillips, B. L., \& Travis, J. M. J. (2010). Trade-offs and the evolution of life-histories during range expansion. Ecology Letters, 13, 1210-1220.

Cadotte, M. W. (2007). Competition-colonization trade-offs and disturbance effects at multiple scales. Ecology, 88, 823-829.

Capellini, I., Baker, J., Allen, W. L., Street, S. E., \& Venditti, C. (2015). The role of life history traits in mammalian invasion success. Ecology Letters, 18, 1099-1107.

Carle, F. L., \& Strub, M. R. (1978). A new method for estimating population size from removal data. Biometrics, $34,621$.

Carlin, B. (1955). Tagging of salmon smolts in the river lagan. Report : Institute of Fresh-water Research, Drottningholm, 36, 5774.

Carlson, S. M., \& Seamons, T. R. (2008). A review of quantitative genetic components of fitness in salmonids: Implications for adaptation to future change. Evolutionary Applications, 1, 222-238.

Carroll, S. P. (2007). Natives adapting to invasive species: Ecology, genes, and the sustainability of conservation. Ecological Research, 22, 892-901.

Cattaneo, F., Hugueny, B., \& Lamouroux, N. (2003). Synchrony in brown trout, Salmo trutta, population dynamics: A “Moran effect" on early-life stages. Oikos, 100, 43-54.

Craig, J. F. F. (1985). Aging in fish. Canadian Journal of Zoology, 63, 1-8. Crozier, L. G., Zabel, R. W., Hockersmith, E. E., \& Achord, S. (2010). Interact ing effects of density and temperature on body size in multiple populations of Chinook salmon. The Journal of Animal Ecology, 79, 342-349.

Elliott, J. M. (1994). Quantitative ecology and the brown trout. Oxford, UK: Oxford University Press.

Fay, R., Barbraud, C., Delord, K., \& Weimerskirch, H. (2016). Variation in the age of first reproduction: Different strategies or individual quality? Ecology, 97, 1842-1851.

Fumagalli, L., Snoj, A., Jesenšek, D., Balloux, F., Jug, T., Duron, O., ... Berrebi, P. (2002). Extreme genetic differentiation among the remnant populations of marble trout (Salmo marmoratus) in Slovenia. Molecular Ecology, 11, 2711-2716.

Gall, G. A. E., \& Crandell, P. A. (1992). The rainbow trout. Aquaculture,100, 1-10.

Garcia de Leaniz, C., Fleming, I. A., Einum, S., Verspoor, E., Jordan, W. C., \& Consuegra, S. (2007). A critical review of adaptive genetic variation in Atlantic salmon: Implications for conservation. Biological Reviews of the Cambridge Philosophical Society, 82, 173-211.

Hendry, A. P., \& Gonzalez, A. (2008). Whither adaptation? Biology and Philoso phy, 23, 673-699.

Jiménez, M. A., Jaksic, F. M., Armesto, J. J., Gaxiola, A., Meserve, P. L., Kelt, D. A., \& Gutiérrez, J. R. (2011). Extreme climatic events change the dynamics and invasibility of semi-arid annual plant communities. Ecology Letters, 14, 1227-1235.

Jones, P. E., \& Closs, G. P. (2015). Life history influences the vulnerability of New Zealand galaxiids to invasive salmonids. Freshwater Biology, 60, 2127-2141.

Jonsson, B., \& Jonsson, N. (2011). Ecology of Atlantic salmon and brown trout: Habitat as a template for life histories. Fish and fisheries series, Vol. 33. New York, NY: Springer.

Jonsson, B., Jonsson, N., \& Finstad, A. G. (2013). Effects of temperature and food quality on age and size at maturity in ectotherms: An experimental test with Atlantic salmon. The Journal of Animal Ecology, 82, 201-210. 
Korsu, K., Huusko, A., \& Muotka, T. (2009). Invasion of north European streams by brook trout: Hostile takeover or pre-adapted habitat niche segregation? Biological Invasions, 12, 1363-1375.

Kurz, M. L., Heins, D. C., Bell, M. A., \& von Hippel, F. A. (2016). Shifts in life-history traits of two introduced populations of threespine stickleback. Evolutionary Ecology Research, 17, 225-242.

Laake, J. L., Johnson, D. S., \& Conn, P. B. (2013). Marked: An R package for maximum-likelihood and MCMC analysis of capture-recapture data. Methods in Ecology and Evolution, 4, 885-890.

Linhart, Y. B., \& Grant, M. C. (1996). Evolutionary significance of local differentiation in plants. Annual Review of Ecology and Systematics, 134, 237-277.

Macarthur, R., \& Levins, R. (1967). The limiting similarity, convergence, and divergence of coexisting species. The American Naturalist, 101, 377. Meldgaard, T., Crivelli, A. J., Jesensek, D., Poizat, G., Rubin, J. F., \& Berrebi, P.

(2007). Hybridization mechanisms between the endangered marble trout (Salmo marmoratus) and the brown trout (Salmo trutta) as revealed by instream experiments. Biological Conservation, 136, 602-611.

Musseau, C., Vincenzi, S., Jesenšek, D., Boulêtreau, S., Santoul, F., Nicolas, D., \& Crivell, A. J. (2017). Dietary niche expansion and niche shift in native marble trout (Salmo marmoratus) living in sympatry with introduced rainbow trout (Oncorhynchus mykiss). Ecology of Freshwater Fish, 27, 720-731. Ogle, D. H. (2018). FSA: Fisheries Stock Analysis. R package version 0.8.21. Retrieved from https://github.com/droglenc/FSA

Olden, J. D., Poff, N. L., \& Bestgen, K. R. (2006). Life-history strategies predict fish invasions and extirpations in the Colorado River Basin. Ecological Monographs, 76, 25-40.

Peterson, D., Fausch, K., \& White, G. (2004). Population ecology of an invasion: Effects of brook trout on native cutthroat trout. Ecological Applications, 14, 754-772.

Platt, J. R. (1964). Strong inference. Science, 146, 347-353. R Development Core Team (2014) R: A language and environment for statistical computing. Vienna, Austria: R Foundation for Statistical Computing.

Ranta, E., Kaitala, V., Lindström, J., \& Helle, E. (1997). The Moran effect and synchrony in population dynamics. Oikos, 78, 136142.

Riester, M., Stadler, P. F., \& Klemm, K. (2009). FRANz: Reconstruction of wild multi-generation pedigrees. Bioinformatics, 25, 2134-2139.

Roff, D. (2007). Life-history evolution. Sunderland, MA: Sinauer Associates Inc.

Ruesink, J. L. (2005). Global analysis of factors affecting the outcome of fresh water fish introductions. Conservation Biology, 19, 1883-1893.

Sakai, A. K., Allendorf, F. W., Holt, J. S., Lodge, D. M., Molofsky, J., With, K. A., ... Weller, S. G. (2001). The population biology of invasive species. Annual Review of Ecology and Systematics, 32, 305-332.

Simon, K. S., \& Townsend, C. R. (2003). Impacts of freshwater invaders at different levels of ecological organisation, with emphasis on salmonids and ecosystem consequences. Freshwater Biology, 48, 982-994.

Southwood, T. R. E. (1977). Habitat, the templet for ecological strategies? The Journal of Animal Ecology, 46, 337-365.

Stankovic, D., Crivelli, A. J., \& Snoj, A. S. (2015). Rainbow trout in Europe: Introduction, naturalization, and impacts. Reviews in Fisheries Science \& Aquaculture, 23, 39-71.

Stearns, S. C. (1992). The evolution of life histories. Oxford: Oxford University Press.

Stearns, S. C., \& Hendry, A. P. (2003). Evolution illuminated: Salmon and their relatives. Oxford: Oxford University Press. 
Strauss, S. Y., Lau, J. A., \& Carroll, S. P. (2006). Evolutionary responses of natives to introduced species: What do introductions tell us about natural communities? Ecology Letters, 9, 357-374.

Sušnik, S., Pustovrh, G., Jesenšek, D., \& Snoj, A. (2015). Population genetic SNP analysis of marble and brown trout in a hybridization zone of the Adriatic watershed in Slovenia. Biological Conservation, 184, 239-250.

Thomson, D. L., Cooch, E. G., \& Conroy, M. J. (2009). Modeling demographic processes in marked populations. New York: Springer.

Valentini, A., Pompanon, F., \& Taberlet, P. (2009). DNA barcoding for ecolo gists. Trends in Ecology \& Evolution, 24, $110-117$.

Vincenzi, S., Crivelli, A., Munch, S., Skaug, H. J., \& Mangel, M. (2016). Tradeoffs between accuracy and interpretability in von Bertalanffy random-effects models of growth. Ecological Applications, 26, 1535-1552.

Vincenzi, S., Crivelli, A. J., Jesensek, D., Rubin, J.-F., Poizat, G., \& De Leo, G. A. (2008). Potential factors controlling the population viability of newly introduced endangered marble trout populations. Biological Conservation, 141, 198-210.

Vincenzi, S., Mangel, M., Crivelli, A. J., Munch, S., \& Skaug, H. J. (2014). Determining individual variation in growth and its implication for life-history and population processes using the empirical Bayes method. PLoS Computational Biology, 10, e1003828.

Vincenzi, S., Mangel, M., Jesensek, D., Garza, J. C., \& Crivelli, A. J. (2016). Within and among-population variation in vital rates and population dynamics in a variable environment. Ecological Applications, 26, 2086-2102.

Vincenzi, S., Mangel, M., Jesensek, D., Garza, J. C., \& Crivelli, A. J. (2017). The genetic and life-history consequences of extreme climate events. Proceedings of the Royal Society B, 284, 20162118.

von Bertalanffy, L. (1957). Quantitative laws in metabolism and growth. The Quarterly Review of Biology, 32, 217-231.

Yano, A., Nicol, B., Jouanno, E., Quillet, E., Fostier, A., Guyomard, R., \& Guiguen, Y. (2013). The sexually dimorphic on the Ychromosome gene $(\mathrm{sd} \mathrm{Y})$ is a conserved male-specific $\mathrm{Y}$-chromosome sequence in many salmonids. Evolutionary Applications, 6 , 486-496.

\section{SUPPORTING INFORMATION}

Additional supporting information may be found online in the Supporting Information section at the end of the article. 